\title{
The frontiers of empirical science: A Thomist-inspired critique of scientism
}

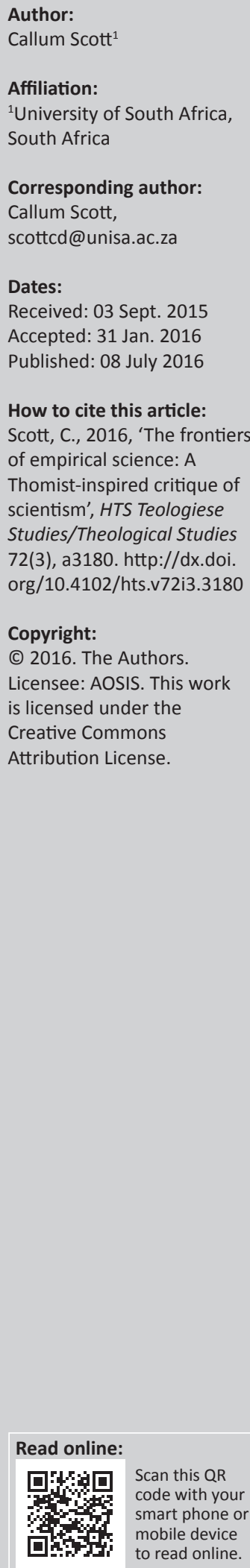

Scientistic conceptualisations hold to the positivistic positions that science is limitless in its potential representations of material phenomena and that it is the only sure path to knowledge. In recent popular scientific literature, these presuppositions have been reaffirmed to the detriment of both philosophy and theology. This article argues for the contrary position by a meta-analysis of empirical science from a Thomist perspective. Identifying empirical science as limited in its method and bound to the material sphere of being alone, we posit that rather than standing as the sole path to the knowledge of being, empirical science is constrained at its frontiers. It is subsequently contended that far from empirical science having the explanatory ability to respond to all presenting scientific problems in principle, fundamentals without the grasp of the methodology of empirical science exist. To relate the article's meta-analysis to scientific praxis, physical cosmology - as the most foundational empirical science-is exemplified in the discussion.

\section{Introduction}

With the limitlessness of scientific knowledge, we mean: there is no question that in principle science cannot answer. (Carnap 1961:254)

Despite numerous publications (cf. Gleiser 2014; Haack 2007; Olafson 2001; Sorrell 1991; Stenmark 2001; Williams \& Robinson 2015) that critique scientistic epistemologies of empirical science, a proliferation of scientism - in the spirit of Carnap - has emerged from the hands of popular science writers, for example, Dawkins (2003), Harris (2006), Hawking (2001), Humphrey (1995), and Hawking and Mlodinow (2010) among others. ${ }^{2}$ In each of these, and many other scientific texts like them, 'science' is reduced to the empirically verifiable alone. By logical consequence, any discipline which cannot be empirically measured - including much philosophical and theological discourse - is excluded from 'knowledge'. Historically, this position emerged from the Humean and positivist understandings of empirical science.

However, the thesis that will be advocated in this article is to the contrary. From a historiographical paradigm it will be developed that empirical science cannot be hypothesised as the singular path to knowledge. Instead, out of an undergirding Thomist paradigm, empirical science will be conceptualised as one among multifarious methodologies of knowledge acquisition (Aquinas, Expositio super Librum Boethii de Trinitate, [1255] 1993:8). While scientism could be critiqued from a hermeneutic perspective, this article attempts to problematise the phenomenon out of the analysis of contemporary empirical science itself, which Saint Thomas, himself, did in his own time ([1255] 1993:8). Utilising this method, a specific analysis of scientific cosmology will be employed as an exemplar, because cosmology ranges in its truth claims across an epistemic spectrum from empirical science to metaphysics. This article is, however, delimited in terms of its scope: I will not determine a metaphysical system that provides account for ultimate causality but lay the groundwork for this by arguing that scientific absolutism is insufficient.

\section{Scientism: reducing being to empiricism}

Although modern, anti-metaphysical physicalism has roots in Hume, it is a more ancient phenomenon (Hume [1748] 2008:86). Leucippus (5th century BCE), for instance, had developed a 1.Translation by the author.

2.Scientism is the conviction that natural science provides the most reliable human account for natural phenomena (Sorell 1991:1). Items of belief which are founded in scientism, such as the absolutist position that '... science is the only valuable part of human learning...' are regarded as 'scientistic' (1991:1).

Note:This article was originally presented as a conference paper at the International Congress on Science and/or Religion: A 21st Century Debate, held from 27th-29th August 2015 at the Sigmund Freud Privat Universität, Vienna, Austria. The author wishes to acknowledge the financial assistance of Prof. R.M.H. Moeketsi, Executive Dean, College of Human Science, University of South Africa and Ms. Y.M. Coetser, Lecturer of Philosophy, Department of Philosophy, Practical and Systematic Theology, University of South Africa for her constructive input in the development of this article. 
materialist atomism, which his student Democritus also embraced (Laertius [c. 250 CE] 1853d], [c. 250 CE] 1853e). Materialism, however, in its positivist sense, only came to the fore in the 19th century's August Comte ([1896] 2000:302-303). ${ }^{3}$ Radically different to premodern 'natural philosophy', Comte's positivism sought to make physical order apparent without appeal to non-empirically verifiable, metaphysical causality (Comte [1896] 2000:302; Crotty 1998:22):

The Positive Philosophy is distinguished... by... its rejection of all inquiry into causes... [thus]... observed facts are the only basis of sound speculation... no proposition that is not finally reducible to the enunciation of a fact... can offer any real and intelligible meaning... (Comte [1896] 2000:302-303)

Fuelled by Comte, the Vienna Circle grounded all valid knowledge in empirical science, chiefly through observation such that patterns in nature could be inferred (Carnap [1966] 2009:329-330; Weinberg 1936:1). In this way science was limited to the empirically observable alone (Carnap [1966] 2009:336-337). The positivist reliance upon sensory observation reached its climax in the work of Ernst Mach, who held firm to the notion that knowledge was the product of the sensorily observable by the scientific subject alone (Mach [1910] 1992:119). Mach therefore questioned nondirectly sensorily experienceable claims to knowledge, including atomic theory, because '... the world consists only of our sensations' (Mach 1914:12, 29, [1910] 1992:123).

It is problematic though that Mach did not consider the value-ladenness of sensory observation, as science is only done out of the embodied, historical experience of the scientific subject. Despite this omission, positivists held that through the senses the obtainment of empirically verifiable and objectively neutral knowledge was assured (Crotty 1998:24-25; Neurath, Hahn \& Carnap, 1929:305). A consequence was the positivist insistence that only the empirically verifiable is scientific, so excluding non-empirical theology, aesthetics, metaphysics, ethics, etcetera (Ayer [1936] 1990:16; Crotty 1998:26).

However, by claiming that all knowledge is sensory in origin, positivism is anomalous, for this entails the metaphysical consequence that metaphysics is itself meaningless (Mach 1914:12). Yet, positivism rejects metaphysics (Weinberg 1936:173, 175-176). To remain consistent, positivism must remain silent on any statement about the nature of the real. Thus, positivists should not infer to any universal about the 'world' that transcends sensory experience of particular observations (Hempel 1950:46). However, this would denigrate their project.

Positivism has strongly assumed the reliability of empirical science as an unquestionable tenet, so excluding alternate knowledge systems (Ayer [1936] 1990:16; Crotty 1998:26-27; Mach 1914:12). Indeed, this same assumption is kept by current advocates of scientism like Carl Sagan (1980:4),

3.Prior to Hume and Comte, Francis Bacon (1561-1626) theorised in a positivist manner that universals are objectively perceivable through the scientific method (Bacon 1854:348).
Stephen Hawking (2001:31) and Richard Dawkins (2003:145). Scientism is rooted in positivist empiricism and verificationism, and is similarly a form of physicalism in positing that if only nature exists, then only a method of knowledge acquisition of the physically measurable is valid (Almeder 1998:1; Haught 2006:14). This central hypothesis of scientism, is, however, self-destructive of scientism because contrary to its own standpoint, scientism transcends physically available data. This is so since experienceable entities do not declare in observations thereof, that only empirical science has epistemic value. ${ }^{4}$ Indeed, this negation is a value imposition by some scientists upon the object of their investigations.

The impetus behind scientism is the grand hope that science will eventually explain all that there is to explain within the evolving cosmos (Carnap 1961:254). However, this reduces ontology because of the limitations of scientists. In fact, the tentativity of scientific theories should be sufficient cause for scientistic scientists to temper their belief in the unbounded possibilities of empirical scientific inquiry. It should be emphasised at this moment, that I am not querying the efficacy of the scientific method. Rather, I seek to problematise the absolutism that scientismists have in their perceived unlimited and unbound scientific method as an ultimate, verifiable source for human understanding (Bogen 2002:128).

\section{The limits of empirical science}

Our knowledge about the Universe has an edge. (Barrow [1998] 2005:252)

Physical and natural science arise from the human potential to understand extra-subjective entities via empirical conceptualisation. This process is, above all else, a human interaction with nature. However, it is in this same encounter that the limitations of the scientific method necessarily arise (Barrow [1998] 2005:249). Specifically, these limits are located

4.The theory that only empirical facts have epistemic meaning is supported by the Wittgensteinian 'theory of meaning' (Weinberg 1936:35, 175, 195). Wittgenstein attempted to develop a correspondence between linguistic expressions and '... the world' (Weinberg 1936:35; Wittgenstein 1922:27).

It is clear that however different from the real one an imagined world may be, it must have something... in common with the real world. (Wittgenstein 1922:27)

The logical positivists' epistemic approach sought to identify foundational, atomic facts which are 'immediately verifiable in experience...', that is, through direct observation (Weinberg 1936:38, 173, 177).

In order to discover whether the picture [a metaphorical term for a cognitive construct] is true or false we must compare it to reality (Wittgenstein 1922:28).

To establish the truth or falsity of any language claim, though, the content of the claim needs to be empirical, such that it can be verifiable (Weinberg 1936:52). Thus, 'logical simples' - objects which can be reduced no further - need to exist (1936:52). Wittgenstein's argument for the existence of these simples proceeds thus:

If the world had no substance, then whether a proposition had sense would depend on whether another proposition was true.

It would then be impossible to form a picture of the world true or false (1922:27). However, argues Weinberg, Wittgenstein assumed that simples exist in his attempt at proving them to exist (1936:54). Moreover, the concept of simple, elementary facts negates the fact that the empirical world is one of extraordinary complexity (Eric Chaisson 2001; Martin Drenthen, Jozef Keulartz and James Proctor 2009; (Eric Chaisson 2001;

Contrary then to Wittgenstein's attempted defence of atomic facts, simples cannot be logically or empirically substantiated. It therefore appears that the positivist claiming that only empirical facts have meaning is problematic (Weinberg 1936:195). 
at the point of diversion between the empirically knowable and unknowable (Barrow [1998] 2005:1).

Immanuel Kant delineated between the extant limits and non-existent boundaries of empirical science.

...[B]oundaries always presuppose a space existing outside a certain definitive place, and enclosing it; limits don't require anything like that, but are mere negations, indicating of some quantity that it isn't absolutely complete. (Kant [1783] 2007:62)

For Kant, the boundary of science is defined in terms of science's exploratory ability. Thus, while Kant held that science's potential theoretical content - as representative of appearance - is limited to current science, it is not bound at all in terms of what it is potentially able to explore as '... it doesn't recognise that outside it there's something it can't ever reach' (Kant [1783] 2007:62).

Kant's distinction draws out the strengths and weaknesses of the scientific method. Although the history of science clearly demonstrates the efficacy of the method, science is not universal for some parts of the real that are not reducible to the empirical mode of enquiry. Still, Kant demonstrated the modern proclivity for empirical science in his position that science would grow in perpetuity. History offers support to this evolutionary interpretation of scientific theory development; theories emerge to better explain observations (Kant [1783] 2007:62). However, boundaries of scientific theories do not exist for Kant. Thus, in Kant's estimation, science is unbounded in what it can potentially explain.

The principle difference between Kant's insight into scientific theories and positivism and scientism is that Kant appreciates the spatio-temporal limitations imposed on science while the latter consider science as absolute (Harris 2006). Instead of espousing a naïve philosophy of science, Kant ([1783] 2007) cautioned that science is temporally limited:

[Scientific] limits... should not be thought of as boundaries -for mathematics bears only on appearances, and so it has no dealings with anything that can't be an object of sensible intuition, such as the concepts of metaphysics and of morals, which means that it has no dealings with anything that could be a boundary for it. Mathematics can never lead to such things, and has no need for them. So there is a continual progress and approach towards completion in these sciences, towards the point or line, so to speak, of contact with completeness. (p. 62).

Is it necessary for different disciplines to be cut off from one another, as Kant expresses? From a Thomist paradigm, I respond in the negative, for herein multiple modes of knowing are not exclusively bounded to disciplines in which knowledge is conceptualised as a continuum of understanding of being, which must be grasped as an irreducible whole. In his commentary, Expositio super Librum Boethii de Trinitate, Aquinas delineated between different speculative approaches to knowing ([1255] 1993:8). However, he embraced Aristotle's uniting of science as a singular human capacity ([1255] 1993:5). The human act of speculative understanding, though, is imaged as having different dimensions, classified by what they are dependent on ([1255] 1993:8). 'Natural science', for instance, depends on matter and mathematics for its speculation, while 'mathematics' does not require matter ([1255] 1993:8). 'Metaphysics', however, is contingent upon what is obtained from natural science (i.e. physics) in that we are '... only able to reach what can't be sensed through what can' ([1255] 1993:8). Thus, a continuum of knowledge is argued for. With nuance, Thomists deemed multiple dimensions of being as theorisable in broader knowledge, that is, scientia (Saint Thomas Aquinas, Summa Theologica, I, Q. 85, A. 3). 'The perfect act of the intellect is complete knowledge, when the object is distinctly and determinately known...' (Aquinas, Summa Theologica, I, Q. 85, A. 3). ${ }^{5}$

Although tempering Kant, I do not posit an entirely contraKantian paradigm. I agree that the boundary of any empirical science can be found at the point of encounter between what that science can and cannot theorise over. If one uses the example of evolutionary biology, for the Thomist it is right for the evolutionary biologist to utilise her method and tools in evolutionary biology. The same honour could not be afforded by the particle physicist who fancies himself to be an evolutionary biologist. In a similar manner, if one were to consider the ontological problem of being, the sole response of the mathematical cosmologist on this problem would be ill conceived, for empirical, science can only theoretically postulate within its bounds of 'retrospective causality' (Rescher 1984:10). 'It clearly makes no sense to ask of [a] science what is in principle impossible' (1984:10). The esteem ascribed to each component of 'scientia' does not permit license for absolute independence of existence. Rather, interdisciplinary dialogue should be fostered for scientific knowledge to be reconceptualised in terms of the whole being of anything under scrutiny.

Scholarship has demonstrated the particular limitations apparent in empirical science, such that science - in postpositivist philosophy of science - is postulated as tentative, non-static, space and time bound, and a human representation of an ever-evolving cosmic milieu. I identify three limits apparent in science: natural, methodological and human.

\section{Natural limits of science}

The evolving nature of the cosmos is the primordial limit imposed on the scientific subject's theoretical postulations over the world. Within space-time, physical and natural dimensions of the cosmos are in constant flux implying that knowable certainty is never achievable, as it does not exist. Indeed, it can thus be construed that scientific theories never absolutely grasp facts, for the object of study is always changing. Science appears always to be 'behind' in its postulations in relation to evolving nature. It may be concluded, therefore, that naïve certainty in the allencompassing ability of empirical science is curtailed by the evolving cosmos, itself.

5.The emphasis is the author's own. 
Among the empirical sciences, the particular study of cosmic development is arguably the primaeval point of meeting between philosophy and science because cosmology explores cosmic origins and so overlaps with the most primal of philosophical questions: 'Why does something exist rather than nothing?' (Leibniz [1716] 2006). Moreover, physical cosmology acutely draws out the limits imposed on science by the grandeur of its scope (Barrow [1998] 2005:155). With the entire cosmos as her field of study, the cosmologist is limited to observe a small area. Furthermore, as cosmologists exist within the object of their study, they are unable to separate themselves from the cosmos in an attempt at objectivity. In this way, limits are imposed by both the universe and the abilities of the human in terms of the constrained perspective the scientific subject has of the object (Barrow [1998] 2005:189; Dewdney 2004:2).

Cosmological research can only be undertaken from the limited observational position of the scientist-subject. As such, the problem of induction becomes a particular limit for the cosmologist for observations cannot be theoretically universalised to validly apply to the unknown cosmic whole.

Furthermore, although technical advancements have broadened the horizon of cosmological observation, Cosmic Microwave Background (CMB) radiation is the naturally imposed physical limit past which no cosmologist may pass (Barrow [1998] 2005:160). CMB was discovered by Arno Penzias and Robert Wilsom in 1964, following the initial theoretical postulation made by Robert Dicke (Dicke, Peebles, Roll \& Wilkinson 1965:415; Penzias \& Wilson 1965:1149, 1154; Silk 2009:22, 24). Essentially, CMB is the radiation measured at $2.736 \mathrm{~K}$, which is extensive throughout the universe (Silk 2009:22,25). The presence of CMB indicates that at \pm 379000 years post the initial singularity, the primordial universe was opaque and carried an approximate temperature of $3000 \mathrm{~K}$ (Pasachoff \& Filippenko 2013:512). The current low temperature of the photons which comprise $\mathrm{CMB}$ is accounted for by the increase of their wavelengths and by the expansion of the space-time continuum (2013:512). Although \pm 400000 years after the singularity the universe became transparent, the opaque universe which preceded this epoch is the physical limit of the knowable universe (Pasachoff \& Filippenko 2013:512; Silk 2009:25). In rudimentary terms, the universe, prior to $\mathrm{CMB}$, was simply too opaque, dense and searing for the possibility of the detection of electromagnetic radiation (Pasachoff \& Filipenkko 2013:512). It is, thus, that the cosmologist cannot validly infer an unverifiable postulate relating to the pre\pm 400000 years from the singularity or a hypothesis universalised based on particular, limited observations (Barrow [1998] 2005:160).

A final natural limit imposed on the cosmologist is the consequence of cosmic inflation ([1998] 2005:164). Inflationary cosmological models infer that for a limited period of time after the initial singularity, inflation occurred, but later decayed to a 'normal' rate of expansion ([1998] 2005:164). The inflationary period at $10^{-32}$ seconds after the 'Big Bang' is supported by data from the Planck space telescope (Peplow 2013).
From evidence of the inflationary period, it is theorised that matter emerged in this epoch from tiny fluctuations (Peplow 2013; Silk 2009:38). However, in the post-inflationary decay, data concerning the pre-inflationary epoch were destroyed ([1998] 2005:168-169). It will never be possible for the cosmologist to obtain these data of the primordial period (Barrow [1998] 2005:169).

\section{Cognitive limits of science}

The 'acognitivism' of Bacon, the empiricists and the positivists held that the thinking subject misconstrued the unfiltered content of sensory observations in theory development (Rescher 1984:25). Therefore, these scholars would have preferred that the scientist remains as a passive noter of received sense data without interpretation (1984:25). But, thinking subjects can never be passive recorders (Faust 1984:28; Rescher 1984:54).

Science, the cognitive exploration of the ways of the world, is a matter of the interaction of the mind with nature - of the mind's exploitation of the data to which it gains access in order to penetrate the 'secrets of nature'. (Rescher 1984:54)

As a fallible agent, the human mind imposes its limitations on science (Barrow [1998] 2005:90). The engagement of the mind with data is, for instance, made apparent in the filtering of sensory data, for it is in this process that the relevant is sifted from the superfluous for scientific theories (Faust 1984:8). Indeed, the vastness of observation data held by the subject necessitates filtering through judgement (Faust 1984:9), but, these never absolutely representing being as-it-is (Faust 1984:41-42).

\section{Scientific methodology as a limit of science}

At its most basic methodological plane, empirical science is limited to the study of measurable matter (Medawar 1984:81:86). If this is presumed, it is beyond the methodological capacity of science to explore the non-material (1984:82). In terms of physical cosmology, then, while cosmologists may desire to explore why the cosmos came to be as it is, they can only utilise physical evidence in their theory development because they must remain in empirical science (Russell 2008:12).

The history of science is replete with instances of falsified theories (Medawar 1984:83). The falsifiability of scientific theories is a further limit produced by the scientific method. We can reasonably extrapolate to the likelihood that future scientific theories will similarly be replaced by stronger theories that better represent the correspondence between being and the scientific subject $(1984: 84,88)$. There will, though, be some scientific theories that will endure, for example, Darwin's Theory of Natural Selection has survived despite there being considerable further research undertaken in the field of biological evolution (1859). However, scientific history provides support for the notion of the succession of scientific theories. For instance, Aristotelian physics was the 6.The emphasis is the author's own. 
dominant paradigm from the 4th century BCE until the advent of Newtonian physics in the 17th century (Aristotle [c. 350 BCE] 2006; Newton [1687] 1729). Likewise, Einsteinian relativity theory - in both its particular and general forms superseded Newton in the early 20th century. (Einstein [1905] 2011, [1916] 2007). The tentativity of scientific theories implies that one cannot naively assert the explanatory ability of theories without questioning their potential falsification or future adaptation (Rescher 1984:86).

However, a further methodological limit imposed on scientific methodology is time. Scientific methodology explores the past, for even the present is no longer present but already history when theorising is done. Accordingly, science is always bound to a momentary study of past observation data.

The scientific project, I conclude, is both a limited and fallible enterprise. Consequently, the scientistic normative value placed on the authority of science must be problematised. Indeed, all that science can adequately construe is what the human is able to currently conceptualise in light of the subjective and technical limitations imposed on the scientist, and the currently perceivable in terms of available data.

\section{The boundedness of empirical science's theories}

\begin{abstract}
... [S]cience does not make assertions about ultimate questions - about the riddles of existence, or about man's task in the world. This has often been well understood. But some great scientists, and many lesser ones, have misunderstood the situation. (Popper 1978:342)
\end{abstract}

Science has restrictions on its explanatory ability, chiefly because it is a human, fallible attempt at conceptualising the cosmos. In this vein, it must be emphasised that the human engaged in the activity of science is not as a languid reproducer of objective, matter-of-fact sensory data. Rather, science is a human enterprise among others - although science is better verifiable by empirical measurement than others - all of which are limited by human inability. This is a stance, though, contrary to the unlimited hopefulness in the science of empiricists, positivists and scientismists.

Apart from the limits of science, I propose that knowledge remaining only upon the observed plane denigrates the multiple layers of being of the thing explored. I argue that in the interaction between subject and thing, a more profound problem than the way the object appears cries out for response by the subject. This arises from the possibility that there can be an encounter between the subject and thing which directs to the primordial metaphysical problem: why is that thing? Consequently, a more nuanced grasp of the fullness of the thing's ontology - which empirical science cannot give - is demanded by the fact that it is.

Kant appreciated that existence necessitates metaphysical inquiry which empirical enquiry cannot respond to as it is not in the sphere of the competence of empirical science to metaphysically speculate (Kant [1787] 2010:38; Wittgenstein 1922:16). The decisions to either ignore metaphysical problems by dismissing them as irrelevant to empirical science or by pushing them back from response by finding alternate scientific accounts for being does not remove the metaphysical problem that being needs to be accounted for. Indeed, the appeal to a self-creating cosmos through physical and natural processes merely begs the question of the existence of those processes.

Contrary to the Kantian position that there are no boundaries in particular science - in support of Mary Midgely - I argue that the true boundary of empirical science lies in the impossibility of empirical science from moving across its frontier to account for the metaphysical problem of being (Kant [1783] 2007:62; Midgely 2010). In this manner, empirical science does not provide explanation for the existence of anything, curtailed as it is to provide extrapolations only of things as they appear to the subject and which can be measured empirically to develop verifiable and falsifiable theories. The consideration of the metaphysical problem of the existence of being, therefore, needs to be done.

\section{The metaphysical problem of being coming into being}

The philosophy of the historic roots of science is in natural philosophy (Gracias 1992:3). However, unlike the reductive, physicalist conceptualisation of philosophy of science, 'natural philosophy' was an attempt to conceptualise observed phenomena while remaining open to metaphysics, as was apparent in Aristotle's physics (Aristotle, Physics, I, 1). However, in the 17th century's Enlightenment, Aristotle's physics was replaced by the empirical physics of Galileo and Newton (McMullin 1969:37). After this, natural philosophy was considered as outdated (McMullin 1969:37). Kant, the Enlightenment figure par excellence, further severed the natural philosophical intimacy between science and philosophy by carrying on the Cartesian leaning in favour of empirical science (Descartes [1644] 2012:22, 42; Kant [1787] 2010:37). Thus, while 'science' considered the empirical alone, from early modernity the meta-analysis of scientific method and theories was reserved for philosophy (McMullin 1969:29).

From the Enlightenment, philosophy has not been overly concerned with scientific content as it is the realm of the scientist. But, I wish to posit an alternative: to aid in ontological understanding of the objects of scientific study, the philosophy of science should be expanded to include consideration of the empirical contents of natural philosophy. This is accomplishable by reorienting philosophy of science away from scientific method and theory alone to include things scrutinised by science in its study. By returning to ontology, nature is given primacy as the origin of philosophy of science rather than the analysis of theory and method being its beginning. Thus, a realist paradigm is prospectively adoptable, for the ontological principle must always be 
acknowledged that prior to theories about being, being is (McMullin 1969:54).

The Enlightenment prejudice that severed philosophy from science has not, however, lessened in contemporary scholarship. For instance, Davies (1977) argues:

It is a striking thought that ten years of radio astronomy have taught humanity more about the creation and organization of the universe than thousands of years of religion and philosophy (p. 211).

Nevertheless, cosmology does not provide a theoretical explanation of all being for it is limited in its pursuits and bound to that which it has competence and ability to empirically explore. I consider that such allegiance to scientific cosmology apart from philosophy is unjustified given the evident constraints upon science (Ellis [1975] 1998:120, 199). Certainly, without being able to 'observe' the universe as a whole, the cosmologist must assume that certain non-observable conditions are apparent ([1975] 1998:119-120). Without accessing these non-observables, however, the assumption presumed is not empirically verifiable ([1975] 1998:120). The basis of cosmological exploration is hence not empirically founded but only theoretically inferred.

Scientific cosmology is of particular importance to philosophy as it touches intimately upon the metaphysical themes of 'origins' and 'creation' (Davies 1977:211; [1984] 1998:237, 241; Gamow [1954] 1998:68; Hawking \& Mlodinow 2010:123). This is highlighted by the fact that the empirical data of cosmology cannot respond to the questions posed by cosmology without philosophical investigation. For example, scientific cosmologists postulate theories like the multiverse or the quantum vacuum to account for the physical state of the present cosmos prior to the initial singularity but still do not account for being. ${ }^{7}$ Philosophically, however, questions such as 'why are these postulated states extant at all?' can be posed (Narlikar 1977:136-137). Thus, while the scientific cosmologist is limited to explore physical states, the metaphysician can survey the existence of those same states of being. Indeed, cosmological endeavours that seek to explain being's existence have a long history (Womack 2005:81). ${ }^{8}$

The question of the coming forth into being - the 'problem of creation' - is the fundamental pursuit of philosophical cosmology, as opposed to the description of states of affairs that properly belongs to physical cosmology (Aquinas, Contra Gentiles, II, Ch. 18, §4). While the latter problem is that

7.Cf. Davies [1984] 1998; Gamow [1954] 1998; Grünbaum 1989; Hawking \& Milodinow 2010; Krauss 2012; Mithani \& Vilenkin 2012; Narlikar [1981] 1998; Susskind 2012.

8.The ancient creation myths of Egypt (3rd millennia BCE), Babylon (1200 BCE) and Israel (700-600 BCE) are among the primordial attempts to account for being (Allen 2000:144; Davies 2001:37; King 1902; Pinch 2002:114). Creation mythology was not directly philosophical, however, with Thales (c. 640-546 BCE) and the other Milesians, Anaximander (c. 610-546 BCE) and Anaximenes (c. 585-528 BCE), accorded as the first philosophical cosmologists (Laertius, [c. 250 CE] 1853a; [c. 250 CE] 1853b and [c. $250 \mathrm{CE}$ ] 1853c). However, the philosophical quest for seekin origins of being has not ceased. The significant difference between ancient and modern cosmologies is empirically measurable scientific data. Still, although scientific cosmology can provide descriptions of the earliest times, it meets a boundary in its inability to account for why anything came to be. of the production of matter out of the material initial singularity, the philosophical problem includes all matter extending as far as the primordial particle or the quantum vacuum for, as material entities, their being must also be theorised over (Erbrich 2008:83).

In exploring the emergence of being the philosopher poses a problem of causality which the positivists avoided in declaring it meaningless (Comte [1865] 2011:4). Nevertheless, it is argued - as Comte admits - that all things in space-time are dependent for their being beyond their own being ([1865] 2011:50). Inasmuch as not a thing can bring forth its own being, Aquinas, for instance, argued that no created thing itself can bring about the being of any other material entity (Quaestiones Disputate de Potentia Dei, Q. 3, A. 5). It is hence outside space-time that the metaphysical theory must concern its exploration. This position is based on the notion that non-contingent matter does not exist, and that a metaphysical theory is required because it is beyond the boundaries of empirical science to postulate about the nonspace-time bound.

We recall that the explanatory power of empirical science is constrained to explore material changes in matter. However, the cause of the emergence of being is not a change in the material but rather the bringing into existence of matter qua matter (Aquinas, Contra Gentiles, II, Ch. 17, §1-2). Without bringing matter into being, no material change would be perceptible, because there would be no thing within which a material change could occur. Indeed, '... before being made, the creature is not' (Aquinas, Contra Gentiles, I, Ch. 19, §4).

'Creation', however, is a troublesome concept. Heraclitus in his theory of panta rhei for instance, inferred that creation did not occur because of the eternal motion of the cosmos (Plato, Cratylus, 401.d). Ancient and more contemporary appeals to change and motion that discount creation fail, however, in not explaining why these processes themselves came to be or why the matter with which they relate has existence. Alternatively, metaphysical accounts that hold creation do posit why things are, as entities dependent for their being (Aquinas, Contra Gentiles, I, Ch. 20, §7).

\section{Empirical science against creation}

Although some empirical scientists critique metaphysical creation theories, it is pertinent to consider whether by referring to 'creation' in their hypotheses they are remaining within the empirical confines of their method. I argue that empirical scientists have transcended their method by having reached the boundary of empirical explicability. For although the primordial flaring forth was a change in matter, the bringing about of the being of the matter of that singularity was not, as '... creation is not a motion or a change...' (Aquinas, Contra Gentiles, II, Ch. 17, §2). I, therefore, propose that in scientists' utilising the theories of empirical science to circumvent theories of creation, the 'problem of creation' is not actually removed from being but diverted away from consideration. 
Narlikar (1977) identifies the initial singularity as creation:

So we have the following description of a big bang Universe. At an epoch, which we may denote by $t=0$, the Universe explodes into existence... The epoch $t=0$ is taken as the event of 'creation'. Prior to this there existed no Universe, no observers, no physical laws. Everything suddenly appeared at $t=0$. (p. 125)

I do not support this view because the temporal origin of being is a material change as opposed to the coming into being from not-being. To the contrary, Grünbaum postulated: '... the genuine problem of the origin of matter-energy or of the universe has been fallaciously transmuted into the pseudo-problem of creation by an external cause' (1989:373). This position needs problematising, however, for does the initial singularity - as a change in the universe's material form rather than creation - remove metaphysical inquiry into the latter? The appeal to physical processes is justified, of course, when referring to changes within extant matter. But these processes neither account for the being of matter nor material processes. Changes in material form at the cosmic level are rightfully the study of scientific cosmology. However, their existence still pleads for explanation, and I argue, in the materialist argument insufficient explanation for their being has been provided. This is made further apparent by Grünbaum's misconceptualisation of 'creation' (1989):

The physical universe as a whole had a beginning a finite time ago as a result of an act of creation out of nothing by a single, conscious external CAUSE or agent. And that external cause or creator is then claimed to be the personal God of the biblical theistic tradition. (p. 379)

I propose that the materialist account has misconstrued the 'problem of creation', because it is not a theory of empirical science. Empirical theories are always bound to causal accounts in space-time, whereas creation refers to nothing temporal. Two types of causality - metaphysical and physical - are merged in this misconstrual into a singular form (Grünbaum 1989:379). The argument is thus a straw man: attention has been distracted away from the fundamental problem of creation.

The metaphysical 'problem of creation' has come to be equated to a temporal act: 'Why, I ask, should the transition from the vacuum state to the expansion require any external cause at all, let alone a divine one?' (1989:393). ${ }^{9}$ However, I assert that creation is not a singularity as described by physical cosmology, for, physical cosmology cannot explain that which is not empirically examinable.

Similarly, ultimate causality is reduced to scientific explanation in quantum cosmology in which the cause of the singularity is hypothesised as an uncaused event within a fine-tuned cosmos (Davies [1984] 1998:226-227, 229). The uncaused quantum vacuum is conceived as possessing the possibility of creating infinite numbers of particles ([1984] 1998:233-235). This is problematic. Although making appeal to causality, the causal action of the being of the materially extant quantum vacuum remains unprovided for ([1984] 1998:241). This, according to Davies, is because causality is non-existent in the quantum vacuum ([1984] 1998:242). Still, the existence of the vacuum begs for metaphysical explanation.

[But i]f quantum theory allows particles of matter to pop into existence out of nowhere, could it also, when applied to gravity, allow space to come into existence out of nothing? And if so, should the spontaneous appearance of the universe 18000 million years ago occasion such surprise after all? (Davies [1984] 1998:244)

The aversion from metaphysical explanation is once more apparent by the question of being's existence being pushed away. Responding to the ultimate riddle of existence has been a considerable issue for cosmologists, particularly when faced off against a cosmos bound by space-time, as Hawking famously noted:

So long as the universe had a beginning, we could suppose it had a creator. But if the universe is really completely self-contained, having no boundary or edge, it would have neither beginning nor end. What place, then, for a creator? (1988:140-141)

Similarly, Lemaitre reminisced about Einstein's problem with the primordial explosion of the singularity: 'No, not this; this too much suggests the creation' (Lemaître in Heller 2000:667).

The physicalist conjecture seems to be that by removing the initial singularity the requirement for causality is removed, too. This has been attempted through the embracement of three theoretical constructions founded in eternity and nonsingularity: eternal inflation, and the cyclical and emergent universes (Mithani \& Vilenkin 2012:1). Eternal universe cosmological models claim to conveniently avoid the singularity and the problem of creation (Gamow [1954] 1998:69; Narlikar [1981] 1998:92). These models attempt to circumvent singularities, despite the convincing argument of Hawking \& Ellis that singularities should be considered (1973:272). Founded in the existence of CMB, they demonstrated, '... there was a singularity at the beginning of the present expansion phase of the universe' (1973:378). ${ }^{10}$ Still, philosophically it must be countered that either in an eternal cosmos or in a temporally bound one, the problem that being is does not disappear.

The eternal inflation model images the universe within the context of inflation comprised of limitless emerging and inflating regions (Borde \& Vilenkin 1994:3305). But, were the universe pictured without future limit, is it necessarily the case that it was without causal beginning? (1994:3305). It appears that no future limit removes the Hawking and Penrose singularity theorems! (Borde \& Vilenkin 1994:3305; Mithani \& Vilenkin 2012:1). I conclude that the apparent cosmological evidence is not sufficient to negate singularities (Borde \& Vilenkin 1994:3307).

The second model that avoids origins is the 'cyclic model' (Steinhardt \& Turok 2002:1436). This model hypothesises that 10.cf. Mithani and Vilenkin (2012:1). 
the cosmos is in a never-ending cycle of expansion and contraction, the product of singularities and 'crunches' (2002:1436). The cyclic model lacks empirical verification, however, relying on inductive conjecture for its future-based predictions. Furthermore, the primordial metaphysical problem is not considered.

The final eternal model that I consider is that of the 'Emergent Universe' (Ellis \& Maartens 2004:224-225). In this model, the universe is metaphorically imaged as an eternally existing egg, from which the expanding universe 'hatches' (2004:225). Located within 'Einstein static' there is no singularity at the 'beginning' of the universe (2004). However, is the metaphorical 'cracking open' of the 'egg universe' not somewhat akin to a singularity out of which all that exists came to be? Furthermore, the existence of the 'egg' itself remains unaccounted for.

Another form of meta-cosmological model than those of eternal models that do not consider the problem of being's existence is the currently popular 'multiverse' hypothesis. ${ }^{11}$ Not only does multiverse theory account for the cosmological narrative, but it also responds to the anthropological need of explaining why humans exist in this universe (Rees 1999:83; Scott 2012:347). According to multiverse theory, this universe is one of a myriad of universes and the singularity at its origins in space-time is but one among many in the broader multiverse (Hawking \& Mlodinow 2010:8-9; Rees 1999:83). In fact, Hawking \& Mlodinow give an exact figure of $10^{500}$ universes existing, all of which are the product of natural, physical processes which remain unexplained for their own existence (2010:8-9, 118-119, 136). Amid so many universes in existence, '.. it becomes inevitable that somewhere the right mix of circumstances will occur...' for carbon-based life to evolve (Ellis 2007:289; Hawking \& Mlodinow 2010:136).

Is there empirical support for this hypothesis? An empirical research project gives some insight to this problem. Feeney, Johnson, Mortlock and Peiris (2011) tried to experimentally verify the impact of collisions between universes upon the CMB present throughout this universe (p. 071301-1). The assumption was made that if a universe collided with another there would be discernible evidence in the form of azimuthal symmetrical imprints (Feeney et al. 2011:071301-1). In their seven-year long study, however, Feeney et al. could find no evidence of cosmic collisions upon the CMB (2011:071301-4). While a hasty conclusion could be inferred that this research falsified the hypothesis, it should be emphasised that all that was falsified was the presupposition that multiple bubble universes would collide into one another if they existed (Scott 2012:351). Hence, the hypothetical multiverse does not provide certain knowledge because it is a hypothesis (Davies 2007:495; Kragh 2009:531; Krauss 2012:126; Scott 2012:351). Furthermore, the multiverse, like its companion hypotheses and theories in empirical science, also fails at providing a theory of everything, for it does not account for the existence of the physical laws that enable the multiverse to exist (Scott 2012:353-354).

11.Rees (1999, 2007), Carr (2007) and Hawking and Mlodinow (2010) support multiverse theory, while opposition has emerged from Davies (2007) and Ellis (2007).

\section{Conclusion}

The importance of science does not lie in its constituting the whole of human knowledge. (Putnam [1975] 1995:xiii-xiv).

Within this article, I have attempted to articulate some frontier points in the scientific project, wherein empirical science is clarified as limited by its method and bound in what it can demonstrate. From a Thomist paradigm, the argument has been put forth that science must be understood as only ever partially objective, for science is the result of thinking subjects engaged in an encounter with objects of which scientific methodology can theoretically construct models. The human origins of science, I have proffered, offers a caution: total trust cannot be placed in the scientific method, as it cannot adequately account for the being of all observation data it has hold of through its methodological reduction of ontology to empiricism.

Empirical science is constrained to what it can explain in terms of its empirical method, which excludes ontology. Because science must use its method, what cannot be explored using empirical means cannot be examined by empirical science. As a matter of logical consequence, problems which are not scientific per se, fall into this class of non-explainability, with the 'problem of creation' serving as one example. 'Creation' refers to the emergence of being from not-being, but this is not a problem for science to explore, as there are no measurable observation data available (Aquinas, Contra Gentiles, II, Ch. 17, §2). In effect, when empirical scientists utilise physical science to explain existence they are overstepping the mark of the capabilities of empirical science. Furthermore, attempted circumventing of the nonscientific nature of cosmic origins demonstrates the paucity of the empirical method in this regard. And still the fundamental metaphysical problem stands unanswered by empirical science:

\section{Why is there something rather than nothing?}

My contention is then that any reductionist system of knowledge, such as scientism, which consciously elects to evade this topic falls short of providing a complete account of being. This is not the case with alternative epistemologies such as theistic-based metaphysics - that place emphasis on ontological fullness.

\section{Acknowledgements Competing interests}

The author declares that he has no financial or personal relationships which may have inappropriately influenced him in writing this article.

\section{References}

Allen, J.P., 2000, Middle Egyptian: An introduction to the language and culture of hieroglyphs, Cambridge University Press, Cambridge.

Almeder, R., 1998, Harmless naturalism: The limits of science and the nature of philosophy, Open Court, Chicago, IL.

Aquinas, Saint Thomas, [c. 1259-1268] 1952, Quaestiones Disputate de Potentia Dei: On the power of God, viewed 1 July 2013, from http://www.dhspriory.org/ thomas/english/QDePotentia.htm 
Aquinas, Saint Thomas, [1264] 1955, in O.P.J. Kenny (ed.), Contra Gentiles, book II: Creation, viewed 7 March 2013, from http://dhspriory.org/thomas/ Creation, viewed
ContraGentiles 2 .htm

Aquinas, Saint Thomas, [1255] 1993, 'Expositio super librum Boethii De Trinitate', in T. McDermott (ed.), Aquinas: Selected philosophical writings, pp. 1-50, Oxford University Press, Oxford.

Aquinas, Saint Thomas, [1265] 2010, Summa theologica: Complete American edition transl. The Fathers of the English Dominican Province, Kindle Edition.

Aristotle, [c. 350 BCE] 2006, Physics, Digireads.com, Lawrence, KS.

Aristotle, [350 BCE] n.d., Physics, viewed 18 September 2014, from http://classics.mit. edu/Aristotle/physics.1.i.htm

Ayer, A.J., [1936] 1990, Language, truth and logic, Penguin Books, London.

Bacon, F., 1854, Novum Organum 1620, in B. Montague (ed.), The works, vol. 3 , pp. 343-371, Parry \& MacMillan, Philadelphia, PA.

Barrow, J.D., [1998] 2005, Impossibility: The limits of science and the science of limits, Vintage Books, London.

Bogen, J., 2002, 'Experiment and observation', in P. Machamer \& M. Silverstein (eds.), The Blackwell guide to the philosophy of science, pp. 128-148, Blackwell Publishers, Inc., Malden, MA.

Borde, A. \& Vilenkin, A., 1994, 'Eternal inflation and the initial singularity', Physical Review Letters 72, 3305-3308.

Carnap, R., 1961, Der logische Aufbau der Welt, Felix Meiner Verlag, Hamburg.

Carnap, R., [1966] 2009, 'Theory and observation', in T. McGrew, M. Alspector-Kelly \& F. Allhof (eds.), Philosophy of science: An historical anthology, pp. 329-343, Blackwell Publishing Ltd, Chichester.

Carr, B., 2007, 'Introduction and overview', in B. Carr (ed.), Universe or multiverse?, pp. 3-27, Cambridge University Press, Cambridge.

Chaisson, E.J., 2001, Cosmic evolution: The rise of complexity in nature, Harvard University Press, Cambridge.

Comte, A., [1896] 2000, The positive philosophy August Comte, transl. H. Martineau, vol. 3. 3 vols, Batoche Books, Kitchener.

Comte, A., [1865] 2011, A general view of positivism, transl. J.H. Bridges, Cambridge University Press, Cambridge.

Crotty, M.J., 1998, The foundations of social research: Meaning and perspective in the research process, Sage, London.

Darwin, C., 1859, On the origins of species by means of natural selection, or the preservation of favoured races in the struggle for life, John Murray, London.

Davies, G.I., 2001, 'Introduction to the Pentateuch', in J. Barton \& J. Muddiman (eds.), The Oxford Bible commentary, pp. 13-27, Oxford University Press, Oxford.

Davies, P.C.W., 1977, Space and time in the modern universe, Cambridge University Press, Cambridge.

Davies, P.C.W., [1984] 1998, 'What caused the big bang?', in J. Leslie (ed.), Modern cosmology \& philosophy, pp. 226-244, Prometheus Books, Amherst.

Davies, P.C.W., 2007, 'Universes galore: Where will it all end?', in B. Carr (ed.), Universe or multiverse?, pp. 487-505, Cambridge University Press, Cambridge.

Dawkins, R., 2003, A Devil's chaplain: Selected essays by Richard Dawkins, Weidenfeld and Nicolson, London.

Descartes, R., [1644] 2012, 'Principles of philosophy', Early modern texts, viewed 28 May 2013, from http://www.earlymoderntexts.com/pdf/descprin.pdf

Dewdney, A.K., 2004, Beyond reason: 8 great problems that reveal the limits of science, John Wiley \& Sons, Ltd, Hoboken, NJ.

Dicke, R.H., Peebles, P.J.E., Roll, P.G. \& Wilkinson, D.T. 1965. 'Cosmic black body radiation', Astrophysical Journal 142, 414-419.

Drenthen, M.A.M., Keulartz, F.W.J. \& Proctor, J. (eds.), 2009, New visions of nature: Complexity and authenticity, Springer, Dordrecht.

Einstein, A., [1916] 2007, 'The foundation of the general theory of relativity', in A.J. Kox M.J. Klein \& R. Schulmann (eds.), The collected papers of Albert Einstein: Volume 6. The Berlin years: Writings, 1914-1917, pp. 146-200, Princeton University Press, Princeton.

Einstein, A., [1905] 2011, On the electrodynamics of moving bodies, viewed 17 May 2013, from http://www.fourmilab.ch/etexts/einstein/specrel/specrel.pdf

Ellis, G.F.R., [1975] 1998, 'Cosmology and Verifiability', in J. Leslie (ed.), Modern cosmology \& philosophy, pp. 119-126, Prometheus Books, Amherst.

Ellis, G.F.R., 2007, 'Multiverses: Description, uniqueness and testing', in B. Carr (ed.) Universe or multiverse? pp. 387-409, Cambridge University Press, Cambridge.

Ellis, G.F.R. \& Maartens, R., 2004, 'The emergent universe: Inflationary cosmology with no singularity', Classical and Quantum Gravity 21, 223-232.

Erbrich, P., 2008, 'The problem of creation and evolution', in M.J. Miller, Congregation of Saint Basils (eds.), Creation and evolution: A conference with Pope Benedict XVI in Castel Gondolfo, Ignatius Press, San Francisco, CA.

Faust, D., 1984, The limits of scientific reasoning, University of Minnesota Press, Minneapolis, MN.

Feeney, S.M., Johnson, M.C., Mortlock, D.J. \& Peiris, H.V., 2011, 'First observational tests of eternal inflation', Physical Review Letters 107(7), 071301-1-071301-5.

Gamow, G., [1954] 1998, 'Modern cosmology', in J. Leslie (ed.), Modern cosmology \& philosophy, pp. 57-69, Prometheus Books, Amherst.

Gleiser, M., 2014, The Island of knowledge: The limits of science and the search for meaning, Basic Books, New York, NY.
Gracias, J.J.E., 1992, Philosophy and its history: Issues in philosophical historiography, State University of New York Press, Albany, NY.

Grünbaum, A., 1989, 'The pseudo-problem of creation in physical cosmology', Philosophy of Science 56(3), 373-394.

Haack, S., 2007, Defending science - within reason: Between scientism and cynicism, Prometheus Books, Amherst, NY.

Harris, S., 2006 'Science must destroy religion', 2 January, viewed 24 October 2014, from http://www.huffingtonpost.com/sam-harris/science-must-destroy-reli_b_13153. htm

Haught, J.F., 2006, Is nature enough? Meaning and truth in the age of science, Cambridge University Press, Cambridge.

Hawking, S.W., 1988, A brief history of time, Bantam Books, New York, NY.

Hawking, S.W., 2001, The universe in a nutshell, Bantam Books, New York, NY.

Hawking, S.W. \& Ellis, G.F.R., 1973, The large scale structure of space-time, Cambridge University Press, Cambridge.

Hawking, S.W. \& Mlodinow, L., 2010, The grand design: New answers to the ultimate questions of life, Bantam Press, London.

Heller, M., 2000, 'Cosmological singularity and the creation of the universe', Zygon 35(3), 665-685.

Hempel, C.G., 1950, 'Problems and changes in the empiricist criterion of meaning', Revue Internationale De Philosophie 41, 41-63.

Hume, D., [1748] 2008, 'An enquiry concerning human understanding', in J. Bennett (ed.), Early modern texts, viewed 9 October 2013, from http://www. earlymoderntexts.com/pdf/humeenqu.pdf

Humphrey, N., 1995, Soul searching: Human nature and supernatural belief, Chatto \& Windus, London.

Kant, I., [1783] 2007, 'Prolegomena to any future metaphysics that can present itself as a science, in J. Bennett (ed.), Early modern texts, viewed 9 May 2013, from http://www.earlymoderntexts.com/pdf/kantprol.pdf

Kant, I., [1787] 2010, The critique of pure reason, transl. J.M.D. Meiklejohn, The Pennsylvania State University, University Park, PA.

King, L.W., (transl.), 1902, Enuma Elish: The epic of creation, viewed 29 May 2013, from http://www.sacred-texts.com/ane/enuma.htm

Kragh, H., 2009, 'Contemporary history of cosmology and the controversy over the multiverse', Annals of Science 66(4), 529-551.

Krauss, L.M., 2012, A Universe from nothing: Why there is something rather than nothing, Simon \& Schuster, London.

Laertius, D., [c. 250 CE] 1853a, 'Book I: Life of Thales', in C.D. Yonge (ed.), The lives and opinions of eminent philosophers, viewed 29 May 2013, from http:// classicpersuasion.org/pw/diogenes/dlthales.htm

Laertius, D., [c. 250 CE] 1853b, 'Book II: Life of Anaximander', in C.D. Yonge (ed.), The lives and opinions of eminent philosophers, viewed 29 May 2013, from http:// classicpersuasion.org/pw/diogenes/dlanaximander.htm

Laertius, D., [c. 250 CE] 1853c, 'Book II: Life of Anaximenes', in C.D. Yonge (ed.), The lives and opinions of eminent philosophers, viewed 29 May 2013, http:// classicpersuasion.org/pw/diogenes/dlanaximenes.htm

Laertius, D., [c. 250 CE] 1853d, 'Book IX: Life of Democritus', Classic Persuasion, in C.D. Yonge (ed.), 'The lives and opinions of eminent philosophers, viewed 18 March 2014, from http://classicpersuasion.org/pw/diogenes/dlleucippus.htm

Laertius, D., [c. 250 CE] 1853e, 'Book IX: Life of Leucippus', Classic Persuasion, in C.D. Yonge (ed.), The lives and opinions of eminent philosophers, viewed 18 March 2014, from http://classicpersuasion.org/pw/diogenes/dlleucippus.htm

Leibniz, G.W.F., [1716] 2006, 'Principles of nature and grace based on reason', Early modern texts, viewed 31 July 2013, from http://www.earlymoderntexts.com/pdf/ leibprin.pdf

Mach, E., 1914, The analysis of sensations and the relation of the physical to the psychica, transl. C.M. Williams, The Open Court Publishing Company, Chicago, IL.

Mach, E., [1910] 1992, 'Sensory elements and scientific concepts', in J.T. Blackmore (ed.), Ernst Mach -A deeper look: Documents and new perspectives, pp. 118-126, Springer Science+Business Media, Dordrecht.

McMullin, E., 1969, 'Philosophies of nature', New Scholasticism 43(1), 29-74.

McMullin, E., 1981, 'Is philosophy relevant to cosmology?', American Philosophical Quarterly 43(1), 177-189.

Medawar, P., 1984, The limits of science, Oxford University Press, Oxford.

Midgely, M., 2010, 'Metaphysics and the limits of science', The Guardian, viewed 28 January 2016, from http://www.theguardian.com/commentisfree/belief/2010/ aug/28/philosophy-science

Mithani, A. \& Vilenkin, A., 2012, 'Did the universe have a beginning?', Proceedings of the 10th International Conference on Gravitation, Astrophysics and Cosmology. Advance online publication, viewed 28 January 2016, from http://arxiv.org/ pdf/1204.4658v1

Narlikar, J., 1977, The structure of the universe, Oxford University Press, Oxford.

Narlikar, J., [1981] 1998, 'Was there a big bang?', in J. Leslie (ed.), Modern cosmology \& philosophy, pp. 90-97, Prometheus Books, Amherst, NY.

Neurath, O., Hahn, H. \& Carnap, R., 1929, Wissenschaftliche Weltauffassung: Der Wiener Kreis, Artur Wolf Verlag, Wien.

Newton, I., [1687] 1729, The mathematical principles of natural philosophy, transl. A Motte, B. Motte, London.

Olafson, F., 2001, Naturlaism and the human condition: Against scientism, Routledge, London. 
Pasachoff, J.M. \& Filipenkko, A., 2013, The cosmos: Astronomy in the new millennium, Cambridge University Press, Cambridge.

Penzias, A.A. \& Wilson, R.W., 1965, 'Measurement of the flux density of CAS A at 4080 $\mathrm{Mc} / \mathrm{s}^{\prime}$, Astrophysical Journal 142, 1149-1155.

Peplow, M., 2013, Planck telescope peers into primordial Universe: Analysis of cosmic microwave background backs sudden 'inflation' after Big Bang, 21 March, viewed 14 May 2013, http://dx.doi.org/10.1038/nature.2013.12658

Pinch, G., 2002, Handbook of Egyptian mythology, ABC-CLIO, Santa Barbara, CA.

Popper, K., 1978, 'Natural selection and the emergence of mind', Dialectica 32(3-4), 339-355.

Putnam, H.W., [1975] 1995, Philosophical papers. Volume I: Mathematics, matter and method. Cambridge University Press, Cambridge.

Rees, M J., 1999, 'Exploring our universe and others', Scientific American 281(6), 78-83.

Rees, M.J., 2007, 'Cosmology and the multiverse', in B. Carr (ed.), Universe or multiverse? pp. 57-75, Cambridge University Press, Cambridge.

Rescher, N., 1984, The limits of science, University of California Press, Berkeley, CA.

Russell, R.J., 2008, Cosmology: From alpha to omega, Fortress Press, Minneapolis, $\mathrm{MN}$
Sagan, C., 1980, Cosmos, Random House, New York, NY.

Scott, C.D., 2012, 'The death of philosophy: A response to Stephen Hawking', South African Journal of Philosophy 3(2), 337-357.

Silk, J., 2009, Horizons of cosmology: Exploring worlds seen and unseen, Templeton Press, West Conshohocken, PA.

Sorrell, T., 1991, Scientism: Philosophy and the infatuation with science, Routledge, London.

Steinhardt, P.J. \& Turok, N., 2002, 'A cyclic model of the universe', Science 296 1436-1436.

Stenmark, M., 2001, Scientism: Science, ethics and religion, Ashgate, Aldershot.

Susskind, L., 2012, 'Was there a beginning?', arXiv:1204.5385 [hep-th].

Weinberg, J.R., 1936, An examination of logical positivism, Kegan Paul, Trench, Trubner \& Co, London.

Williams, R.N. \& Robinson, D.N., 2015, Scientism: The new orthodoxy, Bloomsbury Academic, London.

Wittgenstein, L., 1922, Tractatus Logico Philosophicus. With an introduction by Bertrand Russell, F.R.S, Kegan Paul, Trench, Trubner \& Co., Ltd, London.

Womack, M., 2005, Symbols and meaning: A concise introduction, AltaMira Press, Walnut Creek, CA. 